\title{
12. Los apéndices conversacionales en la argumentación: el caso de ¿cachái?
}

Johan Gille

Uppsala universitet

\section{Introducción}

El análisis de los marcadores discursivos a veces nos lleva a describir funciones que poco parecen tener que ver la una con la otra. Incluso se da el caso en el que se identifican, para el mismo marcador pero en distintos contextos, valores aparentemente opositivos, como p.ej. 'atenuante' e 'intensificador'.

Este estudio se inserta en un proyecto de investigación sobre pautas argumentativas en la conversación, en concreto en el discurso académico chileno, tal como se desarrolla en trabajos en grupo realizados por estudiantes universitarios chilenos. En el estudio se analiza un apéndice que se nos presenta como multifuncional y polivalente -el chileno cachái, originalmente una forma del voseo del verbo cachar- utilizando un método que toma en cuenta tanto el trasfondo histórico del marcador en cuestión como sus características estructurales y usos contextuales. El análisis desembocará en la identificación de una base pragmática del marcador, sobre la cual, argumentamos, se sustentan los usos a los que se presta el marcador en los materiales analizados. Para ello, en el presente trabajo se utilizan métodos de la pragmática histórica (Jucker \& Taavitsainen 20I0) para trazar el desarrollo diacrónico del marcador hasta llegar al estado que podemos observar sincrónicamente, momento en que lo podemos analizar desde una perspectiva interaccional. La hipótesis es que la base pragmática actual de cachái viene determinada por su desarrollo diacrónico y que, además, se puede establecer un vínculo entre los usos históricos y actuales de la forma (cf., p.ej., Schwenter I996 $)^{\mathrm{I}}$.

Cómo citar este capítulo:

Gille, Johan, Los apéndices conversacionales en la argumentación: el caso de ¿̇cachái?. In: Engwall, Gunnel \& Fant, Lars (eds.) Festival Romanistica. Contribuciones lingüisticas - Contributions linguistiques - Contributi linguistici - Contribuições linguisticas. Stockholm Studies in Romance Languages. Stockholm: Stockholm University Press. 20I 5, pp. 239-258. DOI: http://dx.doi.org/IO.I6993/bac.l. License: CC-BY 
Para la descripción sincrónica de las funciones interactivas de cachái analizamos en este trabajo un material que proviene del mundo universitario; más concretamente, consta de trabajos en grupo realizados por estudiantes de una universidad de Santiago de Chile. Las reuniones, que son once en total y engloban un total de 25 horas (O I 50000 palabras transcritas), fueron grabadas en vídeo y posteriormente transcritas. El corpus, denominado Grupes, fue recolectado por un equipo de la Pontificia Universidad Católica de Chile bajo la dirección de Ana María Harvey (Fant \& Harvey 2008; Harvey 2006; Gille 20I2).

A este material principal se añaden otras fuentes para la descripción de las vías de desarrollo del marcador enfocado. En primer lugar, se han utilizado el Corpus del Español (en adelante CDE; Davies 2008-) y el Corpus Diacrónico del Español (Real Academia Española 2005-), a los que se suman otras fuentes valiosas para la descripción diacrónica, como diccionarios generales y especializados, estudios dialectológicos, manuales de español publicados en Chile y estudios anteriores sobre el marcador.

\section{Los apéndices conversacionales}

Cachái pertenece a un subgrupo específico de marcadores discursivos, los apéndices conversacionales (Gille \& Häggkvist 2006; Gille \& Häggkvist 20IO; Gille 2006), caracterizados por ser marcadores parentéticos que dependen estructuralmente de una unidad constituyente de turno (UCT) a la cual se añaden como una adición no integrada, mostrándose esta última característica tanto a nivel sintáctico como prosódico, ya que los apéndices se producen en un grupo entonativo propio. Si bien los apéndices tienen sus características particulares, comparten con otros marcadores discursivos los criterios de ser elementos que se utilizan en la conversación con funciones procedurales, interactivas y metatextuales (Martín Zorraquino \& Portolés Lázaro I999; Schiffrin I987). Estructuralmente dependen de una UCT anterior, pero como elementos estratégicos se dirigen de forma indirecta hacia adelante, al próximo o a los próximos turnos (Lindström 2008), ya que son recursos de los que se valen los hablantes para guiar, de una forma u otra, la interpretación que deben sacar los interlocutores de la UCT a la cual se añade el apéndice y, también, para orientar la participación de los interlocutores en el o los próximos turnos.

En los fragmentos (I)-(4) se reproducen cuatro extractos de nuestros materiales que ejemplifican la relación entre los apéndices, en este 
caso cachái, y distintos tipos de la UCT anfitrión a la cual se añaden. Los ejemplos, además, dan constancia del carácter dinámico de aquellas unidades.

(1) busca como- como se han metido en la política en cuba $\downarrow$ cachái $\downarrow$ pero habla como del / noventa y tres

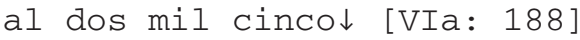

(2) ya $\downarrow$ lo que pasa es que yo tenía un grupo de nede- de negros $\downarrow$ cachái $\downarrow$ ya o afro americanos $\downarrow$ [VIa: 182 ]

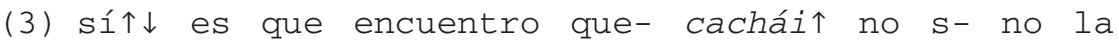
encuentro tan subpoblación $\downarrow$ [VIa: 202]

(4) no sé si estos $\downarrow$ pero a lo mejor me tincaba que

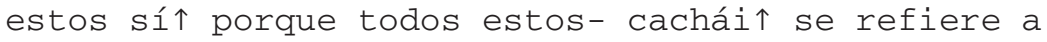
cosas distintas $\downarrow$ [VIa: 39]

En (I) tenemos una UCT completa, a la cual le siguen primero un apéndice y después otra UCT, mientras que en (2) al apéndice le sigue una reformulación de la UCT inicial. En (3), al contrario, la UCT queda incompleta y el apéndice sirve, entre otras cosas, para indicar el término de aquella UCT, después de lo que sigue una reformulación o reparación de la UCT inicial. En (4), finalmente, estamos ante un caso donde el apéndice parece insertarse en medio de una UCT. Sin embargo, al analizar el fragmento más detenidamente observamos que la UCT inicial se produce con un tonema entrecortado, que el apéndice constituye una unidad entonativa propia, y que el verbo en la UCT subsiguiente no concuerda con el sujeto en la UCT inicial ${ }^{2}$. Todos estos datos apuntan a la caracterización del apéndice como justamente apéndice, mientras que la UCT final se construye como un incremento (Lerner 2004) ${ }^{3}$ a la UCT inicial abortada.

Formal, distribucional y semánticamente, los apéndices, al igual que un gran número de marcadores discursivos, han pasado, o están pasando, por un proceso de gramaticalización (o pragmaticalización, cf. Brinton 2010: 303-305; Traugott 2010), mediante el cual se producen, entre otras cosas, debilitamientos semánticos y sintácticos y un enriquecimiento pragmático. ${ }^{4}$ Los usos de los apéndices, sin embargo, siempre reflejan, en mayor o menor grado, los usos y significados anteriores de la forma, por lo que se pueden clasificar en cinco grupos a partir de las funciones básicas que ejercen, las cuales son en cada caso 
vinculadas a una base semántico-pragmática desarrollada de un uso original (Gille \& Häggkvist 2006; Gille \& Häggkvist 20I0):

- Categorización generalizada: o algo así, y tal, y todo esto, etc.

- Posicionamiento: digo yo, yo qué sé, creo /yo/, etc.

- Intersubjetividad:

- comprobativos: ¿no?, ¿sabes?, ¿eh?, ¿cachái? (cf. Ortega Olivares, 1985);

- interpersonales: tío, hombre, etc.

- Autorregulación: por decirlo así (de algún modo), o sea, etc.

- Relaciones o funciones discursivas: pues, po, entonces, nomáh, etc.

Estas funciones de base, a su vez, pueden utilizarse para distintos fines, como veremos en el caso de cachái.

\section{Cachái: origen debatido}

Para tener una base sobre la cual analizar los usos actuales a los que se presta el apéndice en cuestión, resulta, por tanto, fundamental trazar su desarrollo diacrónico. De ese modo, podremos apreciar los cambios graduales que ha sufrido hasta llegar a la situación actual, y tener una visión más completa de su potencial semántico (Linell I998) y, conversamente, de sus restricciones de uso. Sin embargo, en lo que respeta a cachái, que ha salido de la forma voseante del verbo cachar, no constituye una tarea fácil trazar ese desarrollo. En los próximos apartados evaluaremos tres orígenes posibles: uno en un préstamo del inglés catch, otro en una evolución del marcador antiguo cata ahí (y), y finalmente en una evolución del verbo catar.

\subsection{Origen posible 1: catch}

En el Diccionario de la lengua española (Real Academia Española, 200I, s.v. cachar), el origen del uso chileno de cachar (definido como 'entender, comprender') es uno de doce para los que la Academia propone un origen en un préstamo del verbo inglés catch; la misma etimología se repite posteriormente en los pocos estudios sobre cachar y cachái que se han publicado hasta la fecha (Drange 2009; UnzúaCarmona 2006; San Martín Núñez 20II). Esta explicación es relativamente reciente, ya que aparece por primera vez, para el uso chileno, en la vigesimosegunda edición (Real Academia Española 200I, s.v. cachar). 
No obstante, aquella etimología presenta ciertos problemas. En primer lugar, el sentido figurativo que domina en Chile existe pero es improductivo en inglés; allí, más bien, los usos se inclinan claramente hacia sentidos más concretos ( $c f$. Oxford English Dictionary, s.v. catch). Al contrario, en el español chileno, los usos de cachar se relacionan todos a las actividades intelectuales o sensoriales de 'entender', 'comprender', 'pensar', 'ver' y 'mirar', mientras que los sentidos concretos, tan frecuentes en inglés, no se presentan en ningún momento en el español de Chile (Rodriguez I 875; Cavada I914; Morales Pettorino I984; Academia Chilena de la Lengua 20I0). Todo ello apunta a otra etimología para cachar y, naturalmente, también para cachái.

\subsection{Origen posible 2: cata ahi $(y)$}

En el español medieval, el verbo catar se combinaba con los adverbios locativos aquí, y y ahi, formando expresiones con el significado literal de 'mira aquí/ahí'. Gradualmente, a partir de estas combinaciones originalmente libres iba surgiendo un marcador discursivo, del cual tenemos ejemplos a partir del siglo XVII, como el siguiente de Guatemala del siglo XIX, donde cata ahí sirve como una llamada de atención al lector:

(5) Hubo música, toros y cañas; y el hijo del Virrey siempre fué desatendido, mientras el otro paladín, más venturoso, se llevaba tras sí el corazón de la bella. Pero cata ahí que un día el Nerón del hidalgo, cansado de aquellos obsequios, y según se cree, de acuerdo con el Virrey, va y coge a la pretendida y la encierra en un convento, contando con que la soledad y el recogimiento la harían volver al recto sendero. (Milla y Vidaurre, El visitador, I 867 [CDE]).

Este uso discursivo sobrevive regionalmente como catay o catai, en Ecuador y Perú (Alonso 1958: 992), pero también en Chile (Cavada I9I4: 3 I I; Morales Pettorino r984: 925), donde es descrito como una interjección usada en el ámbito familiar para expresar sorpresa.

Es decir, catar en combinación con ahí ha producido algún tipo de marcador, pero hay varias razones por las cuales esta combinación constituye un origen improbable de cachái. En primer lugar, el verbo en cata ahí está en imperativo, mientras que cachái se utiliza exclusivamente en un formato interrogativo. En segundo lugar, es difícil explicar una posible evolución fonética [-ta-] > [-t $\left.\int \mathrm{a}-\right]$, ya que la palatalización de [t], cuando se produce, se da ante la semivocal [j] y, en ciertos contextos, ante la vocal anterior [i] (Corominas I944: 21; 32). Finalmente, dado que cachái ha salido del paradigma verbal de cachar, se requeriría 
de un proceso largo y complejo para que una interjección como catay fuera reanalizada como una forma del voseo para el verbo catar, el cual posteriormente habría evolucionado fonéticamente a cachar antes de producir el resultado final.

\subsection{Origen posible 3: catar $^{5}$}

Hace ya más de cien años propuso Rodolfo Lenz (I905: 844) que cachar "en el sentido fam[iliar] de 'aguaitar', será una variación burlesca del cast. catar o catear". Veamos las posibilidades de tal origen.

En el español medieval, el verbo predominante para expresar percepción sensorial (primordialmente de tipo visual) fue, efectivamente, catar. Su étimo latino, captare, ya había sido usado con el sentido de "tratar de percibir por los sentidos', especialmente el oído y la vista” (Corominas, I 954 , s.v. catar). Es común en todo el Medioevo, con sentidos basados mayoritariamente en una percepción visual, como 'mirar, ver', 'buscar', 'observar, prestar atención', pero también se usa con sentidos ya generalizados, como 'pensar, considerar' (Corominas I954; Alonso I986). En la mayoría de los usos, se vio gradualmente remplazado por mirar, hasta que en el siglo XIX ya no encontramos más que casos muy aislados. El verbo sobrevivió, sin embargo, en varios puntos de América Latina (Sala I 982: 273-275), entre ellos Chile, donde preservó los sentidos de 'mirar' y 'buscar', al mismo tiempo que desarrolló semántica y fonéticamente. Por lo menos desde el siglo XIX, el verbo aparece como catear $^{6}$, a partir de lo cual evolucionó ya en ese mismo siglo hasta el bisilábico catiar ${ }^{7}$, donde posteriormente se produjo una palatalización de $[\mathrm{t}]+[\mathrm{j}]>[\mathrm{t}]$, un cambio que, a juzgar por la observación arriba citada de Lenz, ya estaba en marcha a principios del siglo XX. Durante la primera mitad de ese siglo, coexistían en la escritura las tres formas catear, catiar y cachar (aunque seguramente en distintos ámbitos o con funciones diversificadas), como se puede apreciar en los siguientes extractos ${ }^{8}$ :

(6) Entre, entre a sentarse, compadre. De cerca cateará mejor a los cuyanitos. (Urzúa, Cuentos chilenos, I923)

(7) Catió al tiro que llegaba tarde. (Castro, Froilán Urrutia, I942)

(8) Cachó don Zaca que era un ardid. (Muñoz, Don Zacarías Encina, I932)

Al mismo tiempo que iba evolucionado fonéticamente, se iba produciendo un desarrollo semántico, más concretamente una extensión metafórica gradual, mediante el cual el verbo iba incorporando nuevos sentidos como 'entender', 'darse cuenta' y 'saber'. Los sentidos 
originales ('mirar', 'ver', etc.), sin embargo, no dejaron de existir sino que sus huellas se dejan ver incluso en nuestros materiales conversacionales, por lo que en el caso de cachar tenemos un ejemplo ilustrativo de retención semántica y de layering (Hopper \& Traugott I 993: I24-I26). En la Tabla I se resume de forma esquemática y aproximada9 ${ }^{9}$ la evolución de catar > cachar > cachái.

Tabla 1. El desarrollo captare > cachái

\begin{tabular}{lll}
\hline Forma & Significado(s) & Tiempo \\
\hline $\begin{array}{l}\text { I. Lat. captare } \\
\text { 2. Esp. ant. catar }\end{array}$ & $\begin{array}{l}\text { 'tratar de coger' } \\
\text { 'tratar de percibir por medio de } \\
\text { los sentidos' }\end{array}$ & I I00-c. I400 \\
3. Esp. ant. catar & $\begin{array}{l}\text { 'mirar, buscar, ver, observar, } \\
\text { examinar' }\end{array}$ & I I00-c. I500 \\
4. catear [Chile] ${ }^{\text {I0 }}$ & $\begin{array}{l}\text { 'mirar, buscar, ver, observar, } \\
\text { pensar, adivinar, entender' }\end{array}$ & -c. I930 \\
5. catiar & $\begin{array}{l}\text { 'mirar, buscar, ver, darse cuenta' } \\
\text { 6. cachar }\end{array}$ & $\begin{array}{l}\text {-c. I950 } \\
\text { 'mirar, ver, entender, darse }\end{array}$ \\
7. cachái & cuenta, pensar, saber' & \\
\hline
\end{tabular}

\section{Cachái en el español chileno coloquial}

Formalmente, cachái es una forma del voseo chileno del verbo cachar. Las formas del voseo en Chile, que generalmente son menos extendidas que las del tuteo, se asocian al habla informal y a situaciones marcadas por un alto grado de solidaridad entre los hablantes (Rivadeneira Valenzuela, 2009: I 86-I 87) ${ }^{\text {II }}$. Si bien el voseo se usa en todo el país, es especialmente común entre hablantes jóvenes del Chile central (ibid.). En consecuencia, las formas del voseo no se usan generalmente en la variedad escrita, ni en situaciones marcadas por un alto grado de formalidad y/o por un bajo grado de solidaridad.

En cuanto al verbo cachar, tiene, según el Diccionario de uso del español de Chile (Academia Chilena de la Lengua 20Io, s.v. cachar) cuatro acepciones distintas: (I) percibir con la visión o los oídos; (2) conocer, tener conocimiento; (3) entender, comprender; (4) suponer, creer. El marcador cachái, mientras tanto, ha sido descrito como una herramienta "para comprobar que se tiene la atención del interlocutor 
durante una narración o conversación" (ibid.), para asegurarse de que el interlocutor ha entendido y para organizar una narración (Drange 2009: I7I), y como un operador pragmático con valores fundamentalmente argumentativos (Montecino 2004: I 8). Es decir, el marcador parece ser multifuncional y polivalente.

Cachái como marcador discursivo es una adición bastante reciente al español chileno que rápidamente ha llegado a ser uno de los más usados, por lo menos entre hablantes jóvenes. San Martín Núñez (20I I) estudió el uso de distintos tipos de marcadores discursivos en diversos grupos de hablantes del español chileno, y encontró que mientras que los hablantes entre los 20 y 34 años usaban cachái con frecuencias muy elevadas $^{12}$, entre hablantes más viejos (mayores de 55 años), el marcador no se presentaba. Otro dato destacado del mismo estudio es que el marcador en cuestión era más frecuente en el habla de hombres que en la de mujeres, con un $72 \%$ de las ocurrencias en el estudio producidas por hombres. Estos datos en conjunto apuntan, según el autor, a un cambio lingüístico en marcha, en el cual cachái va remplazando otros marcadores discursivos anteriormente utilizados para los mismos objetivos (San Martín Núñez 201 I: 162-163).

Efectivamente, el primer ejemplo de cachái que hemos encontrado es reciente; data del I97I y proviene de la novela popular Palomita blanca (Lafourcade I97I), en la cual el apéndice se usa con mucha frecuencia en el diálogo entre jóvenes, sobre todo por parte del protagonista masculino. Cabe sospechar que por aquellas fechas, cachái llevaba cierto tiempo formando parte del español chileno coloquial juvenil, no solo como una forma del paradigma verbal de cachar sino también como marcador discursivo.

Es decir, ya por aquel entonces parece haber empezado el proceso de gramaticalización de cachái, el cual ha proseguido hasta ahora, momento en el cual podremos comprobar que el grado de gramaticalización del marcador es avanzado, aunque no completo. Formal y estructuralmente, cachái ha sido fijado; no admite variación de persona, tiempo o modo, no acepta negación ni prácticamente otro tipo de complementación, y queda reducido a usarse como apéndice y no como elemento integrado. Además, está pasando por un proceso de reducción fonética (cachái > c ${ }^{2}$ chái), y ha experimentado un aumento considerable en frecuencia de uso, de modo que el marcador supera con mucho en frecuencia a otras formas no gramaticalizadas del verbo ${ }^{\mathrm{I}}$. Aun así, los criterios de gramaticalización no se cumplen por completo, por lo que cachái ha de considerarse un marcador en una etapa avanzada de gramaticalización. 


\subsection{Función de base: llamada de atención}

Cachái constituye, tanto formal como convencionalmente, una pregunta absoluta que sirve para pedir una comprobación mínima, es decir, una retrocanalización ${ }^{\mathrm{I}}$. Para describir las funciones de cachái, por tanto, debemos tomar en cuenta el tipo de información que invita. Según Allwood, Nivre \& Ahlsén (I992), la retrocanalización sirve para expresar cuatro funciones básicas: contacto (sí/no te estoy prestando atención), percepción (sí/no te estoy oyendo), comprensión (sí/no te comprendo), y reacciones actitudinales (sí/no estoy de acuerdo). Visto desde la perspectiva del marcador que invita la expresión en uno o varios de estos niveles, se puede calificar a cachái como una llamada de atención al interlocutor y a una unidad informativa ( $c f$. Fuentes Rodríguez I990: I 88; Redeker 2006). Independientemente del nivel en que se pida la comprobación mediante cachái, la petición constituye una llamada de atención ${ }^{15}$ al interlocutor para que coopere de una forma u otra. Esta función, que concuerda con los sentidos perceptivos de cachar que vimos anteriormente, es la función de base de cachái, de la cual se han derivado las demás funciones que veremos a continuación.

\subsection{Cachái y la gestión intersubjetiva}

Para el nivel de reacciones actitudinales, que más nos interesa a la hora de estudiar la argumentación, cachái constituye una llamada de atención, pero no necesariamente una llamada a la participación, sino una invitación a compartir una información, y la valoración de ella. Esta función también se da en narraciones. Por lo tanto, una traducción adecuada de cachái no sería '‘entiendes?' sino más bien '¿lo ves?' o ‘¿te das cuenta?'. Mediante estos apéndices, el hablante presenta el contenido (y su valoración del mismo) como algo que no está bajo discusión, sino que solo le corresponde al interlocutor compartir o no aquel contenido y su valoración. Por tanto, constituye un recurso útil en la gestión intersubjetiva, lo cual, en nuestra opinión, es una -aunque no la únicade las razones de la popularidad de cachái en el habla chilena. En el siguiente extracto tenemos un caso ilustrativo de esta función.

\section{Extracto 9 .}

I C: tú decís que es la- es una teoría que está 2 aceptada $\downarrow$ pero que se pone a prueba de nuevo $3 \quad[$ para: - ]

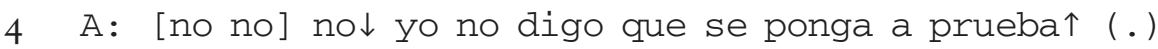
5 como que se investigue y se confirme $\uparrow$ cachai $\uparrow$ 
6 B: y cuál es la diferencia entre repetir la teo7 ría y investigar la hipótesis $\downarrow \S$

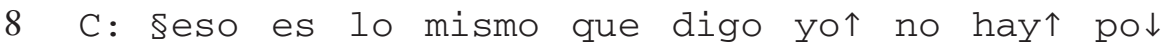
9 entonces así está de más $\downarrow$

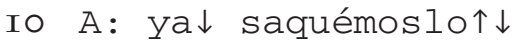

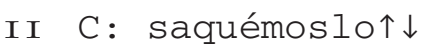

[VIa: 354-359]

El extracto empieza con un resumen por parte de $\mathrm{C}$ de una argumentación anterior desarrollada por A; inmediatamente después, A se opone a la conclusión del resumen y presenta otra versión, al final de la cual añade cachái, que en el contexto sirve como una herramienta para invitar a los interlocutores, y específicamente a C, a compartir esta conclusión como la adecuada. El desenlace del extracto lleva, sin embargo, a otro resultado, donde A acepta quitar este contenido del informe que están elaborando. ${ }^{16}$

\subsection{Cachái y la organización discursiva}

El marcador estudiado también ejerce funciones relacionadas con la organización discursiva; más concretamente, mediante cachái el hablante puede marcar la transición de un plano discursivo a otro, por ejemplo a la hora de iniciar o finalizar una cita (directa o indirecta). Abajo incluimos un ejemplo de ello, donde también se puede apreciar la función anterior, de invitación al interlocutor a que comparta la información anterior, y la valoración de ella, aunque en este caso en una narración más bien que en una argumentación.

\section{Extracto 10 .}

I C: sabis qué $\rightarrow$ yo tenía un artículo que se llamaba- una persona que se llamaba $\rightarrow$ emanuel $\uparrow$ emanuel $\uparrow$ emanuele $\uparrow$

4 B: pero emanuele es mujer $\uparrow$

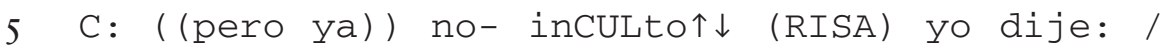

6 ah esto es como francés $\uparrow$ y es:- quiere decir

7 emmanuel $\uparrow$ en francés $\downarrow$ / cachái $\uparrow$ y yo primero

8 le puse hombre $\uparrow$ y después viendo la página

9 web de la: lista de [la facultad de:] =

IO $B$ :

II A:

[ (RISA) ]

[ah: ( (ya sé))]

I2 C: =ciencia política 


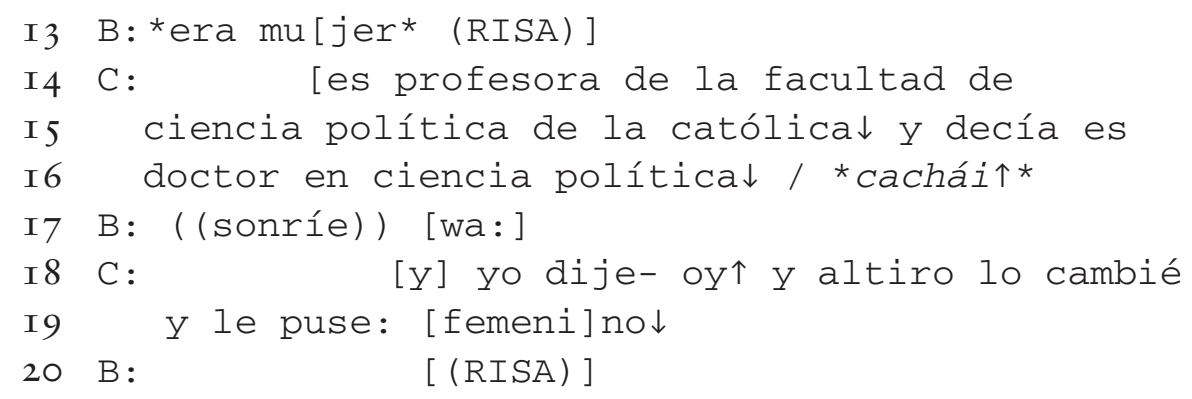

[VIa: 526-536]

Los dos usos de cachái en este extracto (líneas 7 y I6) aparecen en momentos de transición discursiva; el hablante pasa de citas directas a otros planos discursivos, en el primer caso a la narración misma y en el segundo caso a la resolución de la secuencia narrativa. Tanto en el primero como en el segundo caso, la función de invitar a compartir una valoración (o evaluación) de la información queda patente, aunque, en contraste con el ejemplo anterior, en este caso narrativo, la evaluación remite al carácter supuestamente gracioso del incidente mientras que en la secuencia argumentativa la evaluación se halla en un nivel argumentativo, donde una evaluación compartida es lo mismo que un acuerdo.

\subsection{Cachái y la autorregulación}

La tercera función identificada en los materiales se asocia al nivel discursivo de la autorregulación. En estos casos el hablante utiliza el apéndice para marcar como concluida la unidad anterior antes de iniciar otra, lo cual, por ejemplo, puede servir como un recurso para iniciar una autorreparación, sin correr el riesgo de perder el turno.

\section{Extracto 11 .}

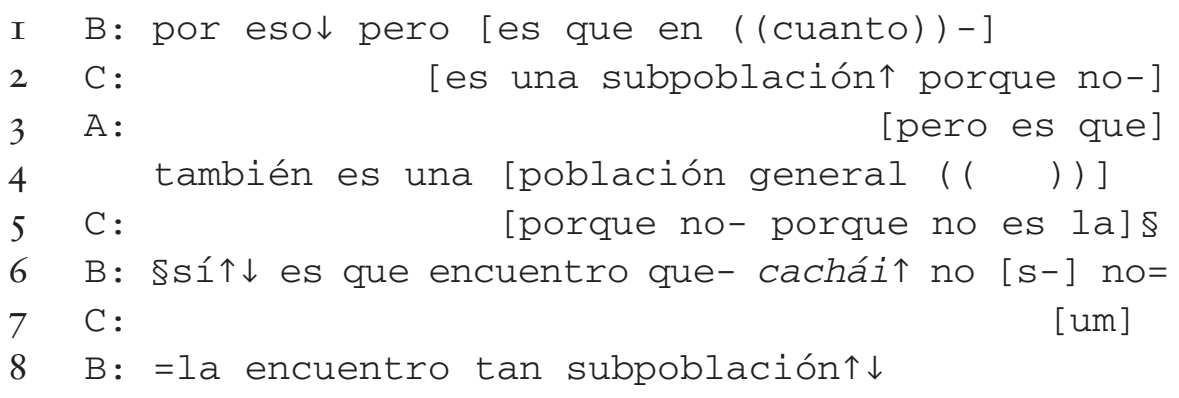

[VIa: I97-203]

En el momento de donde se ha sacado este fragmento, la discusión gira en torno a la posible categorización de un cierto grupo de personas como 
una "subpoblación". C argumenta en la línea 2 a favor de esta categorización, a lo cual contesta A (líneas 3-4), argumentando en contra de la misma. En la línea 6, el tercer participante, B, expresa su acuerdo con la opinión de A, y después continúa elaborando una justificación para esta postura. Sin embargo, entrecorta su primera UCT, marca mediante cachái que concluyó la unidad anterior y se autorrepara, expresando esta vez la justificación (no la encuentro tan subpoblación). Como se ve, en este caso el marcador sirve para marcar la transición de una unidad abortada a otra. No cabe duda de que la función de base del marcador (llamada de atención) sirve de sustento también a este uso, ya que sirve como toque de atención al interlocutor para que se dé cuenta de la transición de la unidad abortada a una nueva unidad.

\subsection{Cachái y la negociación del turno}

En nuestros materiales también hemos dado con algunos casos que parecen indicar que el marcador analizado ejerce una función adicional, hasta ahora no descrita, mediante la cual el hablante al mismo tiempo que se sirve de la función de base del marcador también la utiliza para controlar o retomar el turno, mayoritariamente en contextos argumentativos. Este uso, en el que cachái se produce como primer elemento de una nueva intervención, puede, por una parte, considerarse una extensión del uso autorregulativo, el cual también se puede ver como una estrategia para no perder el turno a la hora de iniciar una autorreparación, y, por otra, como un uso específico de la función intersubjetiva, donde el hablante invita al interlocutor a compartir una valoración, sobre todo en secuencias argumentativas. En el siguiente extracto queda ejemplificado este uso.

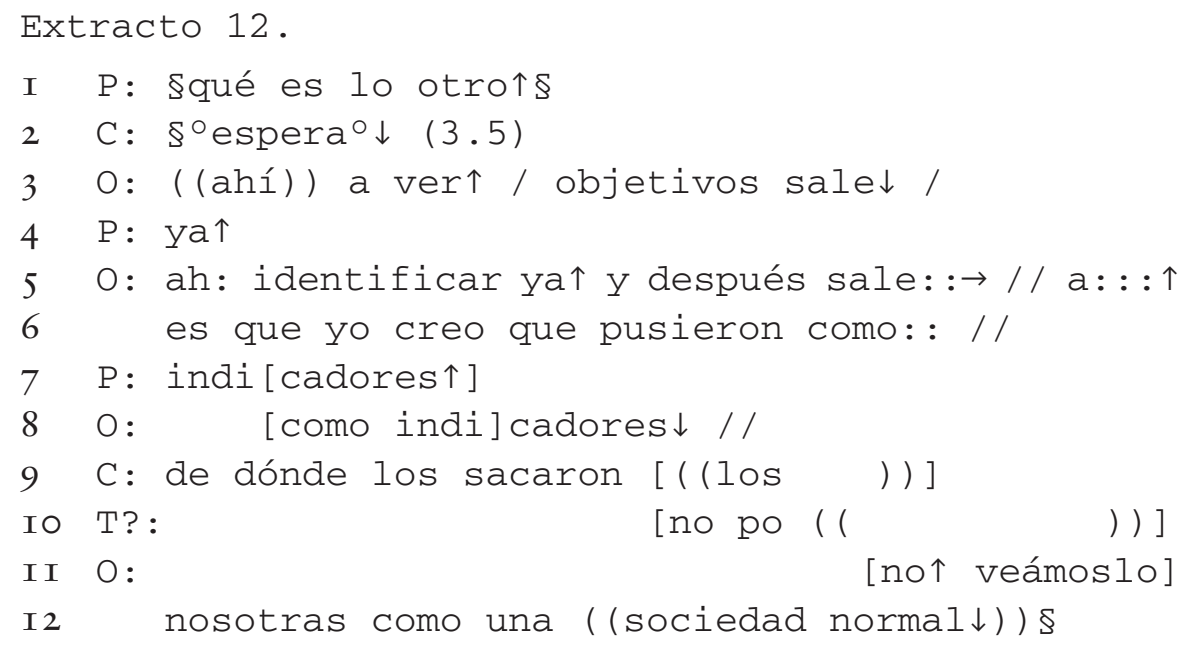




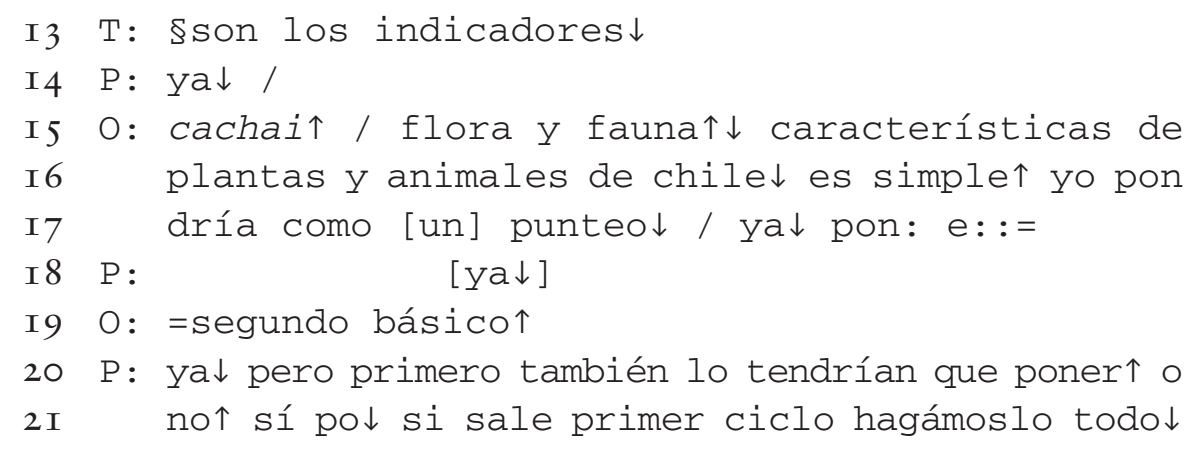

[XI: I338-I353]

Como se aprecia, en la línea I $_{5}$, O retoma mediante cachái el hilo de la argumentación que empezó a desarrollar en su turno anterior (líneas I I-I 2). Este uso podría posiblemente indicar un nuevo desarrollo del marcador, donde sirve no solo como herramienta dentro del propio turno, sino también en la organización interactiva de la distribución del turno. Desde el punto de vista de la descripción de los apéndices conversacionales, y para el análisis de la construcción progresiva e interactiva del turno, este uso nos podrá aportar información valiosa, si bien quedará para trabajos futuros profundizar sobre ello.

\subsection{Cachái y la distribución de roles}

En adición a los usos discursivos, las características estructurales y la función de base del apéndice implica que cachái, del mismo modo que sabes, entiendes, ves, viste, etc., también constituye una herramienta para la negociación y distribución de roles conversacionales. Específicamente, mediante cachái, el hablante le pide al interlocutor que preste atención a lo que está haciendo, lo cual implica necesariamente un intento por parte del hablante de controlar el tipo de participación que puede tener el interlocutor en ese momento ( $c f$. Schiffrin I987). La participación proyectada es restringida, al menos al nivel del turno; la distribución de roles proyectada mediante cachái posiciona al hablante como ocupante de turno y al interlocutor como un participante a quien le corresponde prestar atención al hablante. Por lo tanto, no debe sorprender que en nuestros materiales, cachái se encuentre mayoritariamente a mitad de turno y no como término del mismo.

\section{Conclusión}

En este trabajo se ha esbozado una descripción del marcador discursivo, o apéndice conversacional, cachái, tal como se utiliza en trabajos 
en grupo realizados por estudiantes chilenos. Para poder dar cuenta de forma adecuada y coherente de las funciones de este apéndice -que a primera vista parecen ser muy variadas y poco relacionadas entre sí-, estudiamos su desarrollo diacrónico así como sus características estructurales y usos contextuales contemporáneos, a partir de lo cual establecimos una base semántico-pragmática. En el caso de cachái, la función de base fue identificada como una llamada de atención al interlocutor para que, por una parte, preste atención al hablante y a una unidad discursiva, y, por otra, coopere con él de una forma u otra. Esta función de base, a su vez, se utiliza en los materiales analizados en distintos contextos y para distintos fines, entre los que identificamos usos en la gestión intersubjetiva, la organización discursiva, la autorregulación, la negociación del turno, y la distribución de roles conversacionales.

Como hemos podido ver, la evolución diacrónica del marcador cachái, y más concretamente el origen en un verbo de percepción física, contiene las claves para entender, en combinación con sus características estructurales, la base pragmática del marcador así como los usos a los que se presta en un material contemporáneo. Este resultado sirve como una indicación de la importancia de estudiar no solo los usos contextuales de un marcador determinado, sino también el desarrollo diacrónico de la pieza léxica involucrada. Este desarrollo nos aporta información sobre la base pragmática del marcador, la cual, a su vez, determina los usos a los que se puede prestar un marcador discursivo, así como las restricciones de su uso.

\section{Apéndice: convenciones de transcripción}

A :

?:

$\S$

$=$

[

]

(. )

/

/ /

/ / /

Intervención de un hablante identificado como A. Interlocutor no reconocido.

Sucesión inmediata, sin pausa apreciable, entre dos emisiones de distintos hablantes.

Mantenimiento del turno de un participante en un solapamiento.

Lugar donde se inicia un solapamiento o superposición.

Final del habla simultánea.

Micropausa.

Pausa corta, inferior al medio segundo.

Pausa entre medio segundo y un segundo.

Pausa de un segundo o más. 


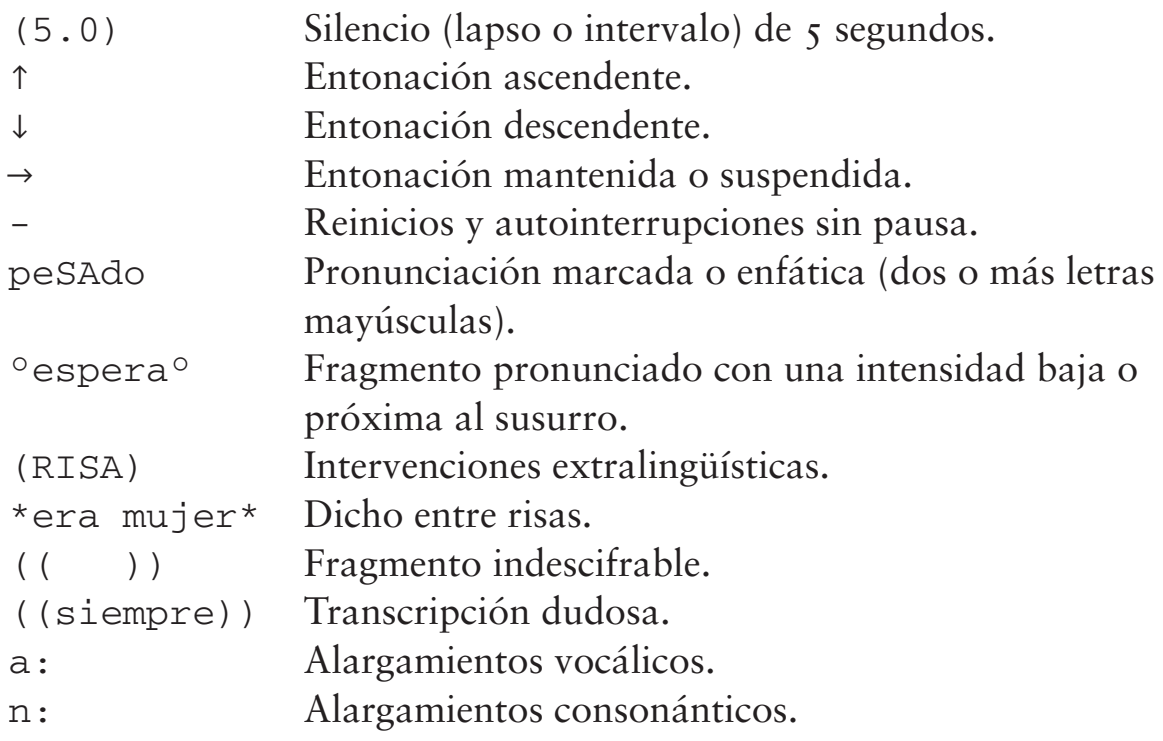

\section{Notas}

I. Dentro del panorama de la pragmática histórica, el presente estudio sigue el modelo denominado "form-to-function mapping" (Brinton 2006), según el cual se describe, paso a paso, la evolución semántico-pragmática de una forma lingüística.

2. Obviamente, este dato en solitario no constituye una prueba concluyente, pero en combinación con los demás puede considerarse otra indicación entre varias.

3. O, en términos de Couper-Kuhlen (2012), una continuación de turno, definida por su característica de depender sintácticamente de la unidad anterior.

4. Los apéndices conversacionales no han llegado siempre a ser completamente gramaticalizados, sino que admiten, por ejemplo, cierta variación y extensión $(y$ cosas lasí; d'esas; como esas/). Además, pueden combinarse entre sí ( $y$ tal, hombre; po cachái; nomáh, po) (cf. Martín Zorraquino \& Portolés Lázaro I999: 4I87)

5. La descripción del desarrollo de catar se basa en Gille (en prensa).

6. Para la evolución -bastante extendida, por cierto- de verbos en -ar > -ear, ver Enguita Utrilla (20I0: 3I4). La evolución también se deja ver en estudios dialectológicos del español de Chile (Medina I928; Rodriguez i 875), así como en libros de estilo (Gormaz, I860).

7. Se trata de una evolución muy extendida por prácticamente todas las zonas de habla hispana desde los tiempos más remotos (Alonso I930: 339-342; Menéndez Pida I940: 275-276; Lapesa 1988: 598, 600). 
8. Sacados todos ellos de Morales Pettorino (I984).

9. La tabla pretende reproducir el desarrollo de forma cronológica, lo cual no significa, sin embargo, que cada paso sea discreto. Más bien, el desarrollo ha sido gradual; formas y significados anteriores gradualmente han dado paso a más recientes. Por ello, y por la relativa escasez de materiales relevantes para ciertos períodos, las extensiones temporales indicadas son aproximadas. Esperamos que futuros estudios puedan arrojar más luz sobre este desarrollo.

Io. La forma catear sigue vigente en Chile, pero solamente con el significado de 'explorar el terreno en busca de una veta minera' (Morales Pettorino I984, s.v. catear).

I I. Cf. también Lipski (1996: 224-226).

I2. En aquel grupo etario, cachái representaba un $87 \%$ de las ocurrencias de los llamados "marcadores de control de contacto" (Briz Gómez I998), los cuales corresponden a los apéndices de intersubjetividad comprobativos (ver supra). De las 874 ocurrencias de cachái en el estudio de San Martín Núñez (20II:I59-I60), 8I7, o el 93,7\%, provenían de hablantes entre los 20 y los 34 años. En nuestros materiales, las frecuencias también son altas; las 825 ocurrencias del marcador representa el 5,6\% del corpus, mientras que en la categoría de los apéndices comprobativos representa el $83 \%$ de los casos.

I3. Frente a las 825 ocurrencias del apéndice gramaticalizado cachái encontramos tan solo 84 ocurrencias de formas no gramaticalizadas del verbo. Es decir, en nuestros materiales cachái es casi diez veces más frecuente que las formas no gramaticalizadas.

I 4. En nuestros materiales, cachái se produce en la mayoría de los casos (73\%) con una entonación ascendente, convencionalmente asociada a unidades informativas que todavía no han llegado a su término ( $c f$. Schiffrin 1987: 29I-295), por ejemplo lo que normalmente llamamos "preguntas".

I 5. Cf. el ejemplo 5 arriba, donde cata abí sirve como una llamada de atención al lector.

I6. Este uso del desacuerdo para eliminar alternativas desacertadas en trabajos en grupo se analiza en Gille (20 I2).

\section{Referencias}

Academia Chilena de la lengua. 20 Io. Diccionario de uso del español de Chile, Santiago (Chile): Asociación de Academias de la Lengua Española.

Allwood, Jens, Joakim Nivre \& Elisabeth Ahlsén. I992. "On the Semantics and Pragmatics of Linguistic Feedback". Journal of Semantics, 9. I-26. 
Alonso, Amado. I930. Problemas de dialectología hispanoamericana. Biblioteca de dialectología hispanoamericana. Buenos Aires: Universidad de Buenos Aires. Facultad de Filosofía y Letras.

Alonso, Martín. I958. Enciclopedia del idioma : diccionario bistórico y moderno de la lengua española (siglos XII al XX) etimológico, tecnológico, regional e hispanoamericano. Madrid: Aguilar.

Alonso, Martín. I986. Diccionario medieval español: desde las Glosas Emilianenses y Silenses (s.X) hasta el siglo XV. Salamanca, Universidad Pontificia.

Brinton, Laurel J. 2006. "Pathways in the development of pragmatic markers". In: Kemenade, Ans Van \& Bettelou Los (eds.). The handbook of the history of English. Oxford: Blackwell.

Brinton, Laurel J. 20I0. “Discourse markers”. In: Jucker, Andreas H. \& Irma Taavitsainen (eds.). Historical pragmatics. Berlin/New York: Walter de Gruyter.

Briz Gómez, Antonio. I998. El español coloquial en la conversación: esbozo de pragmagramática. Barcelona: Ariel.

Cavada, Francisco J. I9 I4. Chiloé y los chilotes. Estudios de folklore y lingüistica de la provincia de Chiloé (República de Chile) acompañados de un vocabulario de chilotismos y precedidos de una breve Reseña Histórica del Archipiélago. Santiago de Chile: Imprenta Universitaria.

Corominas, Joan. I944. "Indianorománica. Estudios de lexicología hispanoamericana". Revista de filología hispánica, VI. I-35.

Corominas, Joan. I954. Diccionario crítico etimológico de la lengua castellana, Madrid: Gredos.

Couper-Kuhlen, Elizabeth. 2012. "Turn Continuation and Clause Combinations". Discourse Processes, 49. 273-299.

Cuenca, Maria Josep \& Maria Josep Marín, 2000. "Verbos de percepción gramaticalizados como conectores: análisis constrastivo español-catalán”. Revista Española de Lingüística Aplicada, I. 2 I 5-237.

Davies, Mark. 2008-. Corpus del Español: Ioo million words, I20os-I9oos.

Drange, Elie M. 2009. "Anglicisms in the informal speech of Norwegian and Chilean adolescents”. In: Stenström, Anna-Brita \& Anette Myre Jørgensen (eds.). Youngspeak in a Multilingual Perspective. Amsterdam/Philadelphia: John Benjamins. I6I-I75.

Enguita Utrilla, José María. 20 Io. "Léxico y formación de palabras”. In: Aleza Izquierdo, Milagros \& José María Enguita Utrilla (eds.). La lengua española en América: normas y usos actuales. Valencia: Universitat de València. 
Fant, Lars \& Ana María Harvey, 2008. "Intersubjetividad y consenso en el diálogo: análisis de un episodio de trabajo en grupo estudiantil”. Oralia, I I. 307-332.

Fuentes Rodríguez, Catalina. I990. “Apéndices de valor apelativo". Sociolingüística andaluza, 5. I7 I-I96.

Gille, Johan. 2006. “'Iraq, y cosas así’: los apéndices conversacionales en español coloquial”. Moderna Språk, ıoo. I 57-ı 66.

Gille, Johan. 201 2. “Va a ser de dos palabras nomás'. El desacuerdo como un recurso en los trabajos en grupo". Onomázein, 25. 26I-285.

Gille, Johan. (en prensa). On the development of the Chilean Spanish discourse marker cachái.

Gille, Johan \& Cilla Häggkvist. 2006. "Los niveles del diálogo y los apéndices conversacionales". In: Falk, Johan, Johan Gille \& Fernando W. Bermúdez (eds.). Discurso, interacción e identidad. Estocolmo, Universidad de Estocolmo.

Gille, Johan \& Cilla Häggkvist. 20ı . "Los apéndices generalizadores introducidos por 0 ". Oralia, I3. I 27-I44.

Gormaz, Valentín. I 860. Correciones lexigráficas sobre la lengua castellana en Chile. Valparaíso: Imprenta del Comercio.

Harvey, Ana María. 2006. "Encuentros orales con fines de estudio: aproximaciones al tema”. In: Falk, Johan, Johan Gille \& Fernando W. Bermúdez (eds.). Discurso, interacción e identidad. Homenaje a Lars Fant. Estocolmo: Universidad de Estocolmo.

Hopper, Paul J. \& Elizabeth C. Traugott I993. Grammaticalization. Cambridge: Cambridge University Press.

Jucker, Andreas H. \& Irma Taavitsainen (eds.). 2010. Historical pragmatics, Berlin, New York: De Gruyter Mouton.

Lafourcade, Enrique. I97 I. Palomita blanca, Santiago de Chile: Zig Zag.

Lapesa, Rafael. I988. Historia de la lengua española, Madrid: Gredos.

Lenz, Rodolfo. I905. Diccionario etimológico de las voces chilenas derivadas de lenguas americanas. Santiago de Chile: Seminario de filología hispánica, Universidad de Chile.

Lerner, Gene H. 2004 “ “On the Place of Linguistic Resources in the Organization of Talk-in-Interaction: Grammar as Action in Prompting a Speaker to Elaborate". Research on Language \& Social Interaction, 37. I 5 I-I 84.

Lindström, Jan. 2008. Tur och ordning: introduktion till svensk samtalsgrammatik. Stockholm: Norstedts akademiska förlag. 
Linell, Per. I998. Approaching dialogue: talk, interaction and contexts in dialogical perspectives, Philadelphia: John Benjamins Publishing.

Lipski, John M. I996. El español de América, Madrid: Cátedra.

Martín Zorraquino, María Antonia \& José Portolés Lázaro I999. "Los marcadores del discurso". In: Bosque, Ignacio \& Violeta Delmonte (eds.). Gramática descriptiva de la lengua española, vol. 3: Entre oración y el discurso. Madrid: Espasa-Calpe.

Medina, José T. I928. Chilenismos. Apuntes lexicográficos. Santiago: Soc. Imp. y Lit. Universo.

Menéndez Pidal, Ramón. I940. Manual de gramática histórica española. Madrid: Espasa-Calpe.

Montecino, Lésmer A. 2004. "Estrategias de intensificación y atenuación en la conversación coloquial de jóvenes chilenos”. Onomázein, Io. 9-32.

Morales Pettorino, Félix. I984. Diccionario ejemplificado de chilenismos y de otros usos diferenciales del español de Chile. Valparaíso: Universidad de Playa Ancha de Ciencias de la Educación.

Ortega Olivares, Jenaro. I985. “Apéndices modalizadores en español: los comprobativos”. In: Montoya Martínez, Jesús \& Juan Paredes Núñez (eds.). Estudios románicos dirigidos al prof. Andrés Soria Ortega en el XXV aniversario de la Cátedra de literaturas románicas. Granada: Universidad de Granada.

Oxford English Dictionary "catch, v.”. OED Online. I 2 Octubre de 20 I 2. Oxford University Press. <http://www.oed.com/view/Entry/288I7? rskey $=\mathrm{g} 6 \mathrm{nMJB} \&$ result $=5$ \&isAdvanced $=$ false $>$.

Real Academia Española. 200I. Diccionario de la lengua española, Madrid: Espasa Calpe.

Real Academia Española. 2005-. Corpus diacrónico del español (CORDE).

Redeker, Gisela. 2006. "Discourse markers as attentional cues at discourse transitions". In: Fischer, Kerstin (ed.). Approaches to discourse particles. Amsterdam: Elsevier.

Rivadeneira Alenzuela, Marcela. 2009. El voseo en medios de comunicación de Chile. Descripción y análisis de la variación dialectal y funcional. Tesis doctoral. Universitat Pompeu Fabra.

Rodriguez, Zorobabel. I875. Diccionario de chilenismos. Santiago: Imp. de El Independiente.

Sala, M. I982. El español de América, Bogotá: Instituto Caro y Cuervo. 
San Martín Núñez, Abelardo. 20I r. "Los marcadores interrogativos de control de contacto en el corpus PRESEEA de Santiago de Chile". Boletín de Filología, XLVI. I35-I66.

Schiffrin, Deborah. 1987. Discourse markers, Cambridge: Cambridge Univ. Press.

Schwenther, Scott A. 1996. "Some reflections on o sea: A discourse marker in Spanish". Journal of Pragmatics, 25. 85 5-874.

Traugott, Elizabeth C. 20Iо. "Grammaticalization”. In: Jucker, Andreas H. \& Irma Taavitsainen (eds.). Historical pragmatics. Berlin, New York: De Gruyter.

Urzúa-Carmona, Paula. 2006. "El verbo "cachar" en el español coloquial de Chile”. Onomázein, I3.97-107. 